\title{
UMAR BIN ABDUL AZIS: ZAMAN KEEMASAN ISLAM MASA DINASTI UMAYYAH
}

\author{
Kori Lilie Muslim \\ LAIN BUkittinggi, liliemuslimkori@gmail.com \\ Melia Afdayeni \\ IAINBukittinggi,meliaafdayeni@gmail.com
}

Diterima: 26 Januari 2019

Direvisi : 16 Mei 2019

Diterbitkan: 30 Juni 2019

\begin{abstract}
The Umayyad dynasty was approximately 91 years old, with 14 leading caliphs. The reign of Umar ibn Azis was regarded as the golden age of the regime, as many of the policies he had done, and that had been prosperity for the people. Different from the governments of the other caliphs, regarded by most historians as the caliphs who made the people in misery. For this, the article aims to analyze the glory achieved by Umar ibn Azis in the reign of the Umayyad dynasty. The methods used are historical research methods, ranging from source search (beuristics) that are limited to historical books in libraries, then criticism of Sember (internal and external criticism), verification and Last is historiography. From the research conducted it can be shown that during the reign of the caliph Umar ibn Abdul Aqiz who did not have a long time to print the history of the glorious civilization, both in terms of the knowledge and life level of society that has been able to enjoy Prosperous life is safe and peaceful. The Baitul Mal by the previous Umayyad caliphs was used as a sovereign or property that is free to be spent by the Palace families. It is different in the time of the end of the Umar because at the time of his treasure Baitul Mal made As the people's. Umar bin Abdul Azir was also very attentive to the hadith as a source of teaching both Islamic teachings. He issued adequate funds to record the hadith to be registered and documented well and neatly and made a scientific reference in religious studies and Islamic legal studies. Not only the badith that received attention, but the science of interpretation, history, and politics is also recorded. In terms of the expansion of the territory of Islam, very few wars in his time because in the development of Islam is more lively by using the advice that is full of wisdom so that many people enter Islam. Thus the reign of the caliphate of Umar ibn Abdul Aziv, which was the Golden age for the Umayyad dynasty.
\end{abstract}

Kata Kunci: Umar ibn Abdul Aziz, Golden Age, Islam, Umayyad Dynasty

\begin{abstract}
Abstrak
Dinasti Umayyah yang berlansung kurang lebih 91 tahun, dengan 14 khalifah yang memimpin. Pemerintahan Umar Ibn Azis dianggap sebagai masa keemasan dinasti ini, karena banyak kebijakan-kebijakan yang beliau lakukan dan hal tersebut mendatangkan kemakmuran bagi rakyatnya. berbeda dari pemerintahan-pemerintahan khalifah yang lain, yang dianggap oleh sebahagian besar sejarawan sebagai khalifah yang membuat rakyat berada dalam kesengsaraan. Untuk itu, Artikel ini bertujuan untuk menganalisis kegemilangan yang dicapai oleh Umar Ibn Azis dalam pemerintahan dinasti Umayyah. Metode yang digunakan adalah metode penelitian sejarah, mulai dari pencarian sumber (Heuristik) yang hanya sebatas pada buku-buku sejarah yang ada di perpustakaan-perpustakaan, kemudian Kritik Sember (kritik internal dan eksternal), ferivikasi dan yang terakhir adalah Historiografi. Dari penelitian yang dilakukan dapat dipaparkan Bahwa pada masa pemerintahan Khalifah Umar bin Abdul aziz yang tidak berlansung lama telah mencetak sejarah peradaban yang gemilang, baik dari segi keilmuan maupun taraf hidup masyarakat yang telah dapat menikmati hidup sejahtera aman dan damai. Baitul Mal yang oleh khalifah-khalifah dinasti umayyah sebelumnya dijadikan sebagai harta penguasa atau harta yang bebas dibelanjakan oleh kelurga istana, hal tersebut berbeda pada masa memerintahan Umar, karena pada masa beliau harta Baitul mal dijadikan
\end{abstract}


sebagai milik rakyat. Umar bin Abdul Aziz juga sangat perhatian terhadap hadits sebagai sumber ajaran kedua ajaran Islam. Beliau mengeluarkan dana yang memadai untuk membukukan hadits agar tercatat dan terdokumentasi dengan baik dan rapi, dan dijadikan rujukan ilmiah dalam studi agama dan kajian-kajian hukum Islam. Bukan hanya hadits yang mendapat perhatian, akan tetapi ilmu tafsir, sejarah dan politik juga dibukukan. Dalam hal perluasan wilayah Islam, sangat sedikit terjadi peperangan pada masa beliau karena dalam perluasan Islam lebih marak dengan menggunakan nasihat yang penuh hikmah sehingga banyak orang yang masuk Islam. Demikianlah pemerintahan kekhalifahan Umar bin Abdul Aziz, yang merupakan masa keemasan bagi dinasti Umayyah.

Kata Kunci: Umar bin Abdul Aziz, Zaman Keemasan, Islam, Dinasti Umayyah

\section{PENDAHULUAN}

Sebelum Rasulullah wafat beliau tidak pernah menunjuk seorangpun yang akan menggantikan beliau sebagai pimpinan politik umat Islam. Hal ini membuat para sahabat Muhajirin dan Anshar melakukan perdebatan yang sengit pasca Rasulullah SAW meninggal dunia, perundingan tersebut diadakan di Tsaqifah bani Saidah (Madinah), yang mana kedua belah pihak sama-sama merasa berhak untuk menjadi pemimpin setelah Rasulullah SAW, sampai akhirnya perdebatan tersebut berbuah kesepakatan kedua belah pihak dengan terpilihnya Abu Bakar RA sebagai Khalifah pertama setelah Rasulullah SAW wafat. Setelah dua tahun menjabat sebagai khalifah Abu Bakar RA digantikan oleh Umar Bin Khatab RA, Utsman Bin Affan RA dan terakhir pada masa pemerintahan Ali Bin Abi Thalib RA. ${ }^{1}$

Pemerintahan selanjutnya dipegang oleh dinasti Umayyah yang berdiri pada tahun $41 \mathrm{H} / 661 \mathrm{M}$ oleh Mu'awiah Bin Abi Sofyan saat itulah pemerintahan Islam yang awalnya bersifat demokratis yang dijalankan oleh Rasulullah SAW dan kemudian dilanjutkan oleh Khulafa Ar-Rasyidin berubah menjadi sistem monarki (kerajaan) berdasarkan garis keturunan $^{2}$ atau dikenal dengan monarki heridetis.

1 Badri Yatim, Sejarah Peradaban ISLAM Dirasah Islamiah II, Jakarta: PT Raja Grafindo Persada, 1994), 35

2 Ibid., 42
Mu'awiyah berhasil mendirikan dinasti Umayyah yang menjadikannya sebagai khalifah pertama. Mu'awiyah mendapatkan kekuasaannya dengan mempolitisi tragedi pembunuhan Utsman Bin Affan RA, tipu muslihat arbitrase dan persiapan kekuatam militer di Syiria. Dinasti Umayyah ini berdiri selama kurang lebih 90 tahun dengan lima khalifah besar diantaranya: Mu'awiyyah bin Abi Sufyan, Abdul Malik Bin Marwan, AlWalid Bin Abdul Malik, Umar Bin Abdul Azis, dan Hisyam Bin Abdul Malik. ${ }^{3}$

Diantara kelima khalifah besar tersebut Umar Bin Abdul Azis yang dikenal sebagai khalifah kelima Khulafaurasyidin, karena pada masa pemerintahan Umar dinasti Umayyah mencapai puncak keemasanya, hal ini ditandai dengan keberhasilan Umar yang membuat hidup umat Islam ketika itu berada dalam kemakmuran dan kedamaian.

\section{BIOGRAFI UMAR BIN ABDUL AZIS}

Umar Bin Abdul Azis lahir di kota yang dulunya bernama Yasrib tetapi setelah kedatangan Nabi Muhammad SAW, kota ini berubah nama menjadi Madinatun Nabi atau Kota Nabi yang sekarang dikenal dengan dengan nama Madinah Al-Munawwarah. Umar lahir pada tahun $63 \mathrm{H} / 682$ M. Umar merupakan keturunan Khulafaurasyidin yang kedua yaitu Umar Bin Khatab RA, karena ibunya merupakan cucu dari Umar Bin Khatab

3 K.Ali, Sejarah Islam Tarikh Pramoderen, (Jakarta: PT Raja Grafindo Persada), 250-251. 
RA yang bernama Laila Ummu Asim Bin Umar Bin Al-Khatab. ${ }^{4}$

Umar memiliki nama lengkap Abu Hafs Umar Bin Abdul Azis Bin Marwan Bin Hakam Bin As Bin Umayyah Bin Abd. Syam. Umar tumbuh sebagai anak yang cerdas dibawah asuhan neneknya di Madinah, sebab ketika itu ayah Umar Bin Abdul Azis menjadi gubernur Mesir dan ibunya hidup bersama ayahnya di Mesir, pada masa pemerintahan Khalifah Abdul Malik Bin Marwan yang merupakan paman Umar.

Di Madinah Umar tumbuh menjadi anak yang cerdas karena bebagian besar gurunya merupakan sahabat Rasulullah SAW, Umar belajar berbagai ilmu seperti periwayatan Hadis, fiqh dan kesusastraan Arab. Berkat ilmunya inilah akhirnya Umar tumbuh menjadi orang yang bijaksana dan disegani oleh masyarakatnya. Umar sangat cinta akan ilmu pengetahuan hal ini tergambar dari kebiasaan Umar yang selalu mempelajari ilmu agama serta menjaga majlis ilmu di Madinah.

Umar Bin Abdul Azis sudah mulai menghafal Alquran semenjak masih kecil, pemahaman Umar tentang Alquran menjadikan beliau sebagai seorang yang shaleh karena Alquran menuntun manusia untuk mengenal Allah SWT, surga, neraka, takdir, dan seluruh aspek kehidupan dunia dan akhirat. Umar sangat takut mendengar kematian serta sering menangisi terhadap yang terjadi pada umurnya. Pernah suatu ketika ibunya mendengar Umar menangis, lalu beliau bertanya kepada Umar, mengapa engkau menangis wahai anakku, lalu Umar menjawab "aku ingat mati” maka saat itupun ibu Umar juga ikut menangis. Hal inilah yang menjadikan Umar sebagai orang yang selalu mempelajari dan mengamalkan Alquran.

Umar muda menyelesaikan pendidikanya dengan sangat baik, makanya

${ }^{4}$ Sayuti Pulungan, 'Umar Bin Abdul Azis' dalam Ensiklopedi Islam, Vol 4. ed. Harun Nasution Et Al (Jakarta: CV.Anda Utama, 1993), 173. beliau diangkat menjadi menantu oleh khalifah Abdul Malik untuk anak perempuannya Fatimah Binti Abdul Malik. Setelah menikah Umarpun diangkat menjadi seorang gubernur di Khusnairah, kota besar sesudah Aleppo di bagian Syiria yang merupakan wilayah kekuasaan dinasti Umayyah pada tahun $85 \mathrm{H}$. Tetapi Pemerintahan Umar di wilayah ini belum sampai dua tahun beliau dipindahkan ke Madinah untuk menggantikan gubernur lama yang seringkali menggelisahkan rakyat. Di Madinah Umar berhasil membawa masyarakatnya ke dalam kedamaian dan kemakmuran oleh karena itu kemudian beliau diangkat menjadi gubernur untuk seluruh tanah Hijaz yaitu Makkah dan Madinah. ${ }^{5}$

Selama enam tahun di Madinah, Umar telah melakukan banyak hal untuk kenyamanan dan ketentraman masyarakat. Salah satu hasil kerja Umar adalah memperluas masjid Madinah, membuat Sumur Umum untuk kepentingan masyarakat. Umar diangkat menjadi khalifah setelah Sulaiman Bin Abdul Malik wafat, menurut riwayat Umar sama sekali tidak menyukai keputusan tersebut sampai suatu ketika, Umar mengumpulkan masyarakat dalam waktu shalat berjamaah di Masjid, kemudian beliau berpidato yang isinya: "Wabai manusia saya telah diuji untuk mengemban tugas kekhalifahan tanpa terlebih dabulu ada yang menanyakan pendapat saya, atau musyawarah kaum muslimin. Oleb karena itu sekarang saya membatalkannya, Maka untuk selanjutnya silabkan kalian pilih khalifah yang kalian sukai". Tetapi ketika itu jama'ah yang hadir mengatakan bahwa mereka telah memilih Umar, dan mereka bersedia diperintah dengan kebahagiaan dan keberkatan. Setelah itu barulah Umar berkata bahwa wajib untuk menta'ati Allah SWT, dan jangan menta'ati orang yang mendurhakai beliau dan ta'atilah

5Armando, "Umar Bin Abdul Azis" Dalam Ensiklopedi Islam, Vol. 3, Ed. Sri Mulyani, Et.Al, Jakarta: PT. Ichtiar Van Houve, 2005), 1252. 
saya selama saya masih ta'at kepada Allah SWT.

Umar Bin Abdul Azis menjabat sebagai Khalifah pada usia 37 tahun, beliau terkenal adil dan bijaksana. Umar bin Abdul Aziz memerintah dengan berpedoman kepada Alquran dan Hadis Nabi SAW. Hal yang pertamakali yang dilakukan Umar adalah adalah dia berjanji untuk menjalankan roda pemerintahan sesuai dengan pedoman yang berasal dari Alquran dan Hadis, sebagai mana telah dipraktekkan oleh Rasul Saw dan empat orang khulafaurasyidin pada masa pemerintahannya.

Kebijakan lain yang dilakukan Umar Bin Abdul Azis adalah melepaskan semua kehidupan yang selama ini penuh dengan kemewahan dan bahkan beliau sadar bahwa harta yang beliau gunakan adalah milik masyarakat, bahkan sampai kendaraan beliau jual kemudian uangnya dimasukkan ke Baitul Mal. Sejak itulah Umar hidup dalam kondisi yang serba sederhana.

Sebuah riwayat mengkisahkan bahwa umar menyuruh istrinya untuk memilih antara dirinya dan perhiasan, karena beliau sadar bahwa perhiasan itupun bukan miliknya. Maka istrinya pun lebih memilih Umar dan menyerahkan perhiasan tersebut ke Baitul Mal. ${ }^{6}$

Selanjutnya Umar bin Abdul Azis membersihkan masyarakat dari perbuatanperbuatan yang melanggar agama, beliau ingin mengembalikan milik Negara kepada Negara karena khalifah-khalifah sebelumnya telah menyalah gunakannya untuk kepentingan pribadi.

Dalam riwayat lain dikisahkan bahwa pada suatu malam datang seorang utusan dari satu daerah, utusan itu mengatakan kepada penjaga bahwa, beritahukan kepada Amirul Mu'minin bahwa yang datang adalah utusan gubernurnya, maka Umar pun

${ }^{6}$ M. Inam Esha, Sejarah Peradaban Islam, (gang Pesantren: UIN Maliki Press, 2011), 89. mempersilahkan utusan itu masuk, kemudian Umar menanyakan kepada utusan tersebut tentang keadaan penduduk kota, keadaan masyarakat yang ada di sana, maka utusan itupun menjawab yang diketahuinya kepada khalifah.

Selanjutnya Umar bertanya tentang apa maksud dan tujuan kedatangan tersebut. Setelah berbincang-bincang Umarpun memerintahkan pelayannya untuk mematikan lilin, lalu utusan itupun bertanya kenapa, lalu beliau menjawab bahwasanya lilin itupun sebenarnya bukanlah haknya.

Umar berkeinginan untuk mengembalikan semua milik rakyat untuk rakyat. Sebab pada masa pemerintahan khalifah-khalifah sebelumnya banyak yang merampok harta milik orang lain di daerahdaerah jajahannya. Menurut Umar harta itu adalah haram. Umar adalah khalifah keturunan Bani Umayyah akan tetapi beliau sangat membenci pelanggaran-pelanggaran hukum agama yang dilakukan oleh pendahulunya tersebut.

Pada masa pemerintahannya Umar Bin Abdul Azis sangat menghargai alim ulama bahkan beliau sering meminta fatwa-fatwa kepada mereka, untuk dijadikan pedoman dalam hidup dan pemerintahan. Walaupun sebenarnya Umar adalah orang yang alim dan sangat dalam ilmu agamanya. Oleh karena itulah Umar sangat disegani dan dihargai oleh masyarakat dan ulama di sekitarnya.

Hal inilah yng membedakan Umar Bin Abdul Azis dengan khalifah-khalifah sebelumnya, Umar adalah orang yang tidah hanya mementingkan dirinya sendiri. Umar juga tampil sebagai seorang pendakwah yang selalu menyeru umat kepada ajaran-ajaran yang diajarkan oleh Rasulullah SAW. Selain itu dia juga terus mengingatkan bahwasanya untuk terus bersyukur kepada Allah SWT telah mengirimkan Nabi Muhammad SAW 
dikalangan mereka hingga akhirnya mereka terlepas dari jalan kesesatan. ${ }^{7}$

Penaklukan pada masa Umar bin Abdul Aziz dilakukan ke Perancis dengan menyeberang pegunungan Baranes. Mereka sampai ke wilayah Septomania dan Profanes, lalu melakukan pengepungan Toulon, sebuah wilayah Prancis. Namun, kaum muslim tidak berhasil mencapai kemenangan yang berarti di Perancis. ${ }^{8}$ Sangat sedikit terjadi perang di masa pemerintahan Umar, dakwah Islam marak dengan menggunkan nasihat yang penuh hikmah sehingga banyak orang yang masuk Islam.

Setelah menjabat sebagai khalifah selama 2,5 tahun, akhirnya Umar menemui ajalnya karena penyakit paru-paru yang dideritanya, tetapi riwayat lain menyebutkan bahwa beliau meninggal karena diracun oleh pelayan suruhan elit Umayyah yang tidak menyukainya, kabarnya pelayan tersebut diberi upah sebanyah 1000 dirham, setelah sahabat memberi tahu Umar atas kelakuan pelayan tersebut, namun beliau berkata bahwa sebenarnya sudah mengetahuinya, maka uang bayaran pelayan itu akhirnya diambil dan dimasukkan ke Baitul Mal, dan beliaupun tidak menghukum pelayan tersebut, hanya saja pelayan itu diperintahkan untuk pergi ketempat yang tidak diketahui orang dan akhirnya meninggal di tempat tersebut.

Selama 20 hari menahan kesakitan akibat racun tersebut, suatu hari beliau berpesan kepada putranya bahwa, harus menjadi orang yang seperti Umar, yang bertaqwa kepada Allah SWT dan terus berbuat baik kepada masyarakat. Akhirnya pada tanggal 20 Rajab $101 \mathrm{H}$ dalam usia 36 tahun lebih 6 bulan beliau menghembuskan nafas terakhirnya di kota Dir Sim'an Syiria

${ }^{7}$ Rizem Aizid, Sejarah Peradaban Islam, (Jakarta: Diva Press, 2015), 56.

8 Ahmad al-Usairy, Sejarah Islam Sejak Nabi Adam Hingga Abad XX, (Jakarta; Media Eka Sarana, 2004), 205 tetapi riwayat lain mengatakan bahwa beliau wafat di Khanasyirah. Atas kematian beliau semua masyarakat menangisinya, bahkan ada yang melantunkan syair-syair duka cita atas kepergiannya.

\section{KEEMASAN DINASTI UMAYYAH}

Dinasti Umayyah mencapai keemasan terjadi pada pemerintahan Umar bin Abdul Aziz. Adapun hal-hal yang membuat Dinasti Umayyah mengalami masa kemajuan yang sangat pesat serta kerja besar yang dilakukan oleh Umar bin Abdul Aziz selama melaksanakan pemerintahan diantaranya adalah mengembalikan semua harta yang ada padanya ke Baitul Mal. Beliau juga memberi kebebasan kepada penganut agama lain untuk beribadah sesuai dengan keyakinan dan kepercayaan

Selama masa pemerintahannya, beliau menerapkan kembali ajaran Islam secara utuh menyeluruh. Pembenahan dilakukan dalam berbagai sektor, dimulai dari diri beliau dan keluarga dengan menyerahkan seluruh harta kekayaan diri dan keluarga yang tidak wajar kepada kaum muslimin dengan cara memasukannya ke dalam Baitul Mal. Tanah perkebunan di Maroko, berbagai tunjangan yang berada di Fadak, Mukaedes, Yaman, Jabal al-Wars, dan Yamah. Bahkan cincin berlian pemberian Al Walid kepada beliau sekalipun. Selama berkuasa Umar bin Abdul Aziz tidak pernah mengambil apapun dari Baitul Mal, termasuk pendapatan fai yang telah menjadi haknya.

Pada masa pemerintahannya, Umar bin Abdul Aziz mengutamakan pembangunan dalam negeri. Karena menurutnya, dengan memperbaiki dan meningkatkan kesejahteraan negeri-negeri Islam adalah lebih baik dari pada menambah perluasan wilayah. Beliau menjaga hubungan baik dengan pihak oposisis dan memberikan hak kebebasan beribadah kepada penganut agama lain. Begitu pula dalam melakukan berbagai kebijakan, beliau bersifat 
melindungi dan meningkatkan kemakmuran dan kesejahteraan masyarakatnya secara menyeluruh.

Masyarakat tidak lagi membayar pajak karena beliau menghapus pajak terhadap muslimin dan mengurangi beban pajak pada kaum nasrani, membuat aturan takaran timbangan, membasmi cukai dan kerja paksa, penggalian sumur-sumur, memperbaiki tanah pertanian dengan menghidupkan dan memperbaiki tanah-tanah yang tidak produktif, dan membuat aturan takaran dan timbangan. Segala kebijakan yang dilakukan Umar bin Abdul Aziz ini berhasil meningkatkan taraf hidup masyarakat secara keseluruhan hingga tidak ada lagi yang mau menerima zakat karena kehidupan mereka sudah berkecukupan dan sejahtera.

Salah satu bukti kesungguhannya dalam menegakkan keadilan, Umar bin Abdul Aziz membelanjakan seluruh kekayaan Baitul Mal di Irak untuk membayar ganti rugi kepada orang-orang yang diperlakukan secara semenamena oleh para penguasa sebelumnya. Karena tidak mencukupi, ia mengambil dari kekayaan Baitul Mal di Syam.

Khalifah Umar bin Abdul Aziz juga menetapkan bahwa para pejabat diberi gaji sebesar 300 dinar dan dilarang melakukan pekerjaan sampingan apapun. Begitu juga pajak yang dikenakan kepada non muslim hanya berlaku pada tiga profesi, yaitu pedagang, tuan tanah, dan petani.

Dalam bidang pertanian, agar tidak ada penguasaan lahan beliau melarang penjualan tanah garapan. Beliau juga memerintahkan amirnya untuk memanfaatkan lahan pertanian yang ada semaksimal mungkin. Khalifah Umar bin Abdul Aziz menerapkan prinsip keadilan dan kemurahan hati, ia melarang memungut sewa terhadap tanah yang tidak subur dan jika tanah itu subur, pengambilan sewa harus memperhatikan tingkat kesejahteraan hidup petani yang bersangkutan, ini dilakukan dalam menetapkan sewah tanah.
Dalam menerapkan kebijakan otonomi daerah, setiap wilayah Islam mempunyai wewenang untuk mengelola pajak dan zakat sendiri-sendiri dan tidak harus menyerahkan upeti kepada pemerintah pusat. Sebaliknya bantuan subsidi kepada setiap wilayah Islam yang minim diberikan oleh pemerintah pusat, baik berupa zakat maupun pajak. Dengan demikian, masing-masing wilayah Islam diberi kepercayaan untuk mengelola kekayaan. Jika terdapat surplus, maka wilayah tersebut memberikan bantuan kepada wilayah yang minim pendapatannya. Dalam hal ini, Ibnu Jahdam sebagai amil shadaqab ditugaskan menerima serta mendistribusikan hasil sedekah secara merata ke seluruh wilayah Islam.

Khalifah Umar bin Abdul Aziz menjadikan jaminan sosial sebagai landasan pokok untuk mewujudkan negara yang adil dan makmur. Hak seorang yang telah meninggal dunia tetap ada karena diberikan kepada ahli warisnya. Begitu pula dengan hak para tahanan diberlakukan secara universal, tanpa membedakan ia seorang muslim atau bukan. Beliau juga mendirikan rumah makan khusus untuk para fakir miskin, kelebihan harta setelah digunakan untuk memenuhi kebutuhan kaum muslimin, pendapatan Baitul Mal didistribusikan kepada orang-orang dzimmi bahkan meraka diberikan pinjaman tanah pertanian sebagai lahan pekerjaan mereka.

Kebijakan jalur perdagangan bebas, baik di Barat maupun di Utara, dikeluarkan oleh Khalifah Umar bin Abdul Aziz untuk meningkatkan taraf kehidupan masyarakat, beliau juga menghapus bea masuk dan menyediakan berbagai bahan kebetuhan sebanyak mungkin dengan harga yang terjangkau.

Pada masa pemerintahan Khalifah Umar bin Abdul Aziz zakat merupakan sumber pemasukan negara. Begitu juga pajak penghasilan pertanian dan hasil rampasan perang. Awalnya beliau meniadakan pajak 
mengingat situasi ekonomi yang belum kondusif namun setelah setelah perekonomian masyarakat membaik maka mulai diterapkan pajak.

Umar bin Abdul Aziz juga sangat perhatian terhadap Hadis sebagai sumber ajaran kedua ajaran Islam. Beliau mengeluarkan dana yang memadai untuk membukukan Hadis agar tercatat dan terdokumentasi dengan baik dan rapi, dan dijadikan rujukan ilmiah dalam studi agama dan kajian-kajian hukum Islam. Hal ini dikerjakan oleh Muhammad bin Syihab azZuhri pada tahun 100H/718 M. ${ }^{9}$ Bukan hanya Hadis yang mendapat perhatian, akan tetapi ilmu tafsir, sejarah dan politik juga dibukukan.

\section{KESIMPULAN}

Sebagai penutup makalah ini, penulis dapat mengambil beberapa kesimpulan bahwa dinasti Umayyah mengalami masa keemasan pada pemerintahan Umar bin Abdul Aziz. Masa pemerintahannya diwarnai dengan banyak reformasi dan perbaikan. Dia banyak menghiduupkan dan memperbaiki tanah-tanah yang tidak produktif, menggali sumur-sumur baru, membangun mesjid, dan kenijakankebijakan yang membuat kemiskinan tidak ada lagi pada zamannya.

Pada masanya sangat sedikit terjadi perang karena dalam perluasan Islam lebih marak dengan menggunakan nasihat yang penuh hikmah sehingga banyak orang yang masuk Islam. Demikian masa dinasti Umayyah dengan masa keemasannya yang terjadi pada masa kekhalifahan Umar bin Abdul Aziz.

9 Faisal Ismail, Sejarah dan Kebudayaan Islam Periode Klasike (Abad VII-XIIIM), (Yokyakarta; IRCiSoD, 2017), 272. 


\section{DAFTAR KEPUSTAKAAN}

Armando, "Umar Bin Abdul Azis" Dalam Ensiklopedi Islam, Vol.3, Ed.Sri Mulyani, Et.Al, Jakarta: PT. Ichtiar Van Houve, 2005

Aizid, Rizem, Sejarah Peradaban Islam Terlengkap, Yogyakarta: Perpustakaan Nasional, 2015

Ahmad al-Usairy, Sejarah Islam Sejak Nabi Adam Hingga Abad XX, Jakarta; Media Eka Sarana, 2004

Aizid, Rizem, Sejarah Peradaban Islam. Jakarta: Diva Press, 2015

Ali, K., Sejarah Islam Tarikh Pramoderen, Jakarta: PT Raja Grafindo Persada

Esha, Muhammad Inam, Sejarah Peradaban Islam, Gang Pesantren: UIN Maliki perss, 2011

Faisal Ismail, Sejarah dan Kebudayaan Islam Periode Klasik. (Abad VII-XIIIM), Yokyakarta; IRCiSoD, 2017

Sayuti Pulungan, 'Umar Bin Abdul Azis' dalam Ensiklopedi Islam, vol 4 ed. Harun Nasution Et Al Jakarta: CV.Anda Utama, 1993.

Yatim, Badri, Sejarah Peradaban Islam Dirasah Islamiah II, Jakarta: PT Raja Grafindo Persada, 1994 